
\title{
Associations of blood mitochondrial DNA copy number with social-demographics and cancer risk: results from the Mano-A- Mano Mexican American Cohort
}

\author{
Hua Zhao ${ }^{1}$, David Chang ${ }^{1}$, Yuanqing Ye ${ }^{1}$, Jie Shen ${ }^{1}$, Wong-Ho Chow ${ }^{1}$ and Xifeng Wu ${ }^{1}$ \\ ${ }^{1}$ Department of Epidemiology, The University of Texas MD Anderson Cancer Center, Houston, 77030 TX, USA \\ Correspondence to: Hua Zhao, email: hzhao2@mdanderson.org \\ Keywords: mitochondrial DNA copy number; cancer risk; lifestyle factors; social context \\ Received: March 22, $2018 \quad$ Accepted: April 16, $2018 \quad$ Published: May 22, 2018 \\ Copyright: Zhao et al. This is an open-access article distributed under the terms of the Creative Commons Attribution License 3.0 \\ (CC BY 3.0), which permits unrestricted use, distribution, and reproduction in any medium, provided the original author and source \\ are credited.
}

\section{ABSTRACT}

The relationship between blood mitochondrial DNA (mtDNA) copy number and subsequent cancer risk has been investigated previously. However, such association has never been examined in Mexican Americans. In the current study, we examined association between social-demographic factors and blood mtDNA copy number, as well as longitudinal relationship between cancer and mtDNA copy number, among 10,802 Mexican Americans in the Mano-A-Mano Mexican American Cohort. Overall, mtDNA copy number was statistically significantly higher among participants who developed cancer during the study period than among cancer-free controls $(0.17$ vs $0.13, P=0.007$ ). Among cancer-free control participants, mtDNA copy number significantly differed by social-demographic characteristics. However, there was a large degree of heterogeneity in these effects across the mtDNA copy number distribution. In the longitudinal analysis, we observed that higher mtDNA copy number was positively associated with increased risk of all cancer types (adjusted hazard ratio $[\mathrm{HR}], 1.13 ; 95 \%$ confidence interval $[\mathrm{CI}], 1.09-1.17)$. Participants with mtDNA copy number in the fourth (highest) quartile had a higher risk of all cancer (adjusted $H R, 2.12 ; 95 \% C I, 1.65-2.73$ ) than did participants in the first (lowest) quartile. In summary, our results in Mexican Americans support an association between increased mtDNA copy number and cancer risk. Our results also suggest that mtDNA copy number may be influenced by social and demographic factors.

\section{INTRODUCTION}

Mitochondrial DNA (mtDNA) is highly vulnerable to oxidative damage because it lacks protection from introns and histones and has less efficient DNA repair mechanisms than nuclear DNA does [1,2]. The number of copies of mtDNA varies widely in humans, ranging from 100 to 10,000 copies per cell, depending on the cell type [3]. Each type of cell or tissue has a fairly constant mtDNA copy number [4]. Precisely how mtDNA copy number is maintained remains poorly understood, but the mechanism probably involves mitochondrial function, energy metabolism, and oxidative damage.

Over the past decade, molecular epidemiologic studies have examined the relationships between mtDNA copy number in leukocytes or whole blood and the risk of several kinds of cancer [5-16]. Positive, inverse, and null associations were reported in those studies. However, whether mtDNA copy number is associated with cancer risk has never been examined in any prospective cohort of adult Mexican Americans.

Indeed, understanding the role of blood mtDNA in cancer risk is particularly important for Mexican Americans, one of the fastest-growing populations in the United States [17]. Three-quarters of Mexican Americans are either overweight or obese $[18,19]$; mtDNA copy number may be a predictive marker of metabolic disturbances, including obesity [20]. Mexican Americans also have a high burden of age-related chronic diseases, such as type 2 diabetes and cardiovascular disease [21-24], both of which are associated 
with mitochondrial dysfunction. Finally, Mexican Americans experience distinctive psychological, somatic, and social stressors associated with immigration and acculturation $[25,26]$. These stressors may affect glucocorticoids and correspondingly influence mitochondria by altering expression of mitochondrial genes and nuclear genes that influence mitochondrial function and copy number [27, 28].

In the current study, our primary hypothesis was that blood mtDNA copy number is associated with overall cancer risk among Mexican Americans. We further hypothesized that blood mtDNA copy number was modified by social, demographic, and lifestyle characteristics at baseline. To test the hypotheses, we measured the relative mtDNA copy number in bloods from 10,802 participants in the large ongoing prospective Mexican American Mano a Mano Cohort Study. We determined the relationship of mtDNA copy number with social, demographic, and lifestyle characteristics at baseline and with the development of cancer subsequently.

\section{RESULTS}

\section{Study cohort characteristics}

A total of 10,802 participants were included in the analysis. Among them, 429 developed cancer during the follow-up period. The mean mtDNA copy number was significantly higher among participants who developed cancer than in the cancer-free control group ( 0.17 vs. 0.13 , $P=0.007)$ (Figure 1).

\section{Factors associated with differences in mtDNA copy number}

We first evaluated whether mtDNA copy number differed by participant characteristics in the 10,373 cancer-free control participants (Table 1). The most significant differences in mtDNA copy number were observed in relation to age, sex, birthplace, and BMI. As age increased, mean mtDNA copy number significantly decreased $(P<0.001)$. Women and participants born in Mexico had significantly higher mean mtDNA copy numbers than did men and US-born participants (both $P<0.001$ ). Mean mtDNA copy number was also significantly higher among overweight participants than among participants who were underweight, normal weight, or obese $(P<0.001)$. In addition, we found that mean mtDNA copy number significantly differed by marital status ( $P=0.024)$, education level $(P=0.024)$, history of alcohol use $(P=0.021)$, and physical activity level $(P=0.016)$, but not by smoking status $(P=0.054)$ or time per day spent on sitting $(P=0.198)$.

\section{Quantile analyses}

To further understand the relationship between mtDNA copy number and selected characteristics in the control group, we performed multivariate unconditional quantile regression analyses. All variables that displayed significant differences shown in Table 1, specifically, age, sex, marital status, education level, birthplace, BMI, alcohol drinking status, and physical activity level, were included in this analysis. Table 2 shows the estimated quantile regression coefficients for 5 selected quantiles (10th, 25th, 50th, 75th, and 90th percentiles) in the control group. Significant inverse relationships were consistently observed between age and mtDNA copy number in all 5 percentiles (all $P<0.01$ ), though the associations became weaker as the percentile increased. Women and participants born in Mexico had higher mtDNA copy numbers than did men and US-born participants, and these correlations were statistically significant at the 25th, 50th, 75 th, and 90th percentiles of mtDNA copy number.

We also found that BMI was associated with mtDNA copy number. Using obese participants as the reference group, we found that at the 10th, 25th, and 50th percentiles, participants who were underweight or normal weight had significantly lower mtDNA copy numbers. Indeed, we observed a trend toward a weaker or even an inverse correlation as the mtDNA copy number percentile increased. However, overweight participants in the 50th, 75th, and 90th percentiles had significantly higher mtDNA copy numbers than did their counterparts in the obese group; the correlation between overweight and higher mtDNA copy number became stronger as the mtDNA copy number percentile increased. Regarding physical activity, participants with medium and high levels of physical activity had higher mtDNA copy numbers than did those with low levels of physical activity, except for participants in the 90th percentile of mtDNA copy number. These associations were significant at the 25th and 50th percentiles. In addition, we observed a weaker and even an inverse association between mtDNA copy number and physical activity as the copy number percentile rank increased.

\section{Association of mtDNA copy number with acculturation and socioeconomic status}

Next, we investigated the relationships between mtDNA copy number and variables measuring acculturation, immigration, and socioeconomic status among cancer-free participants. To measure acculturation, we included a language acculturation score and the preference for Mexican or US food, friends, social activity, heritage, and holidays. For participants who were born in Mexico, the number of years living in the United States and the age at immigration were also included in the analysis. Measures of socioeconomic status included income, home ownership, car ownership, and health insurance status. In addition, we included age, sex, and birthplace in the analysis. Among cancer-free study subjects, those who showed a weaker preference for Mexican friends had significantly higher mtDNA copy numbers $(P=0.011)$. 
However, car ownership was significantly inversely correlated with mtDNA copy number $(P=0.036)$. We next stratified the study cohort by birthplace. We found that among participants born in Mexico, a lower preference for Mexican friends and fewer years of living in the United States were significantly positively correlated with mtDNA copy number ( $P=0.034$ and 0.010 , respectively). Having health insurance was marginally positively correlated with mtDNA copy number for participants born in Mexico $(P=0.080)$. For participants born in the United States, higher levels of language acculturation and lower preference for celebrating Mexican holidays were significantly positively correlated with mtDNA copy number ( $P=0.024$ and 0.008 , respectively). In addition, a marginal inverse relationship was observed between social and car ownership and mtDNA copy number $(P=0.061$ and 0.064 , respectively).

\section{Mitochondrial DNA copy number and cancer risk}

We next examined the relationship between mtDNA copy number and cancer risk (Table 3 ). In the univariate analysis, we found that elevated mtDNA copy number (as a continuous variable) was associated with an increased risk of all cancers (HR, 1.10; 95\% CI, 1.05-1.14). We also identified several other cancer risk factors, including age, sex (male vs female), marital status (other vs married/ living as married), birthplace (US-born vs Mexico-born), BMI (obese vs underweight/normal weight), smoking status (former and current vs never smokers), and alcohol drinking status (current vs never alcohol drinking). In the subsequent multivariate analysis, we included all identified cancer risk factors and mtDNA copy number. The association between elevated mtDNA copy number and cancer risk was slightly stronger than in the univariate analysis (HR, 1.13; 95\% CI, 1.09-1.17). In addition, age, birthplace, BMI, and smoking status remained significantly associated with increased risk of all cancers.

To further assess the relationship between mtDNA copy number and risk of cancer, we stratified the study subjects using the median mtDNA copy number in the noncancer group (0.13) as the cutoff point. We found that those with an mtDNA copy number of 0.13 or higher had a higher risk of all cancers than those with a lower mtDNA copy number (HR, 1.71; 95\% CI, 1.41-2.07) (Table 4). When mtDNA was grouped into quartiles, cancer risk increased significantly with increasing quartile in a dose-response manner $(P<0.001)$, from 1.02 in the second quartile to 1.32 and 2.12 in the third and fourth quartile compared to

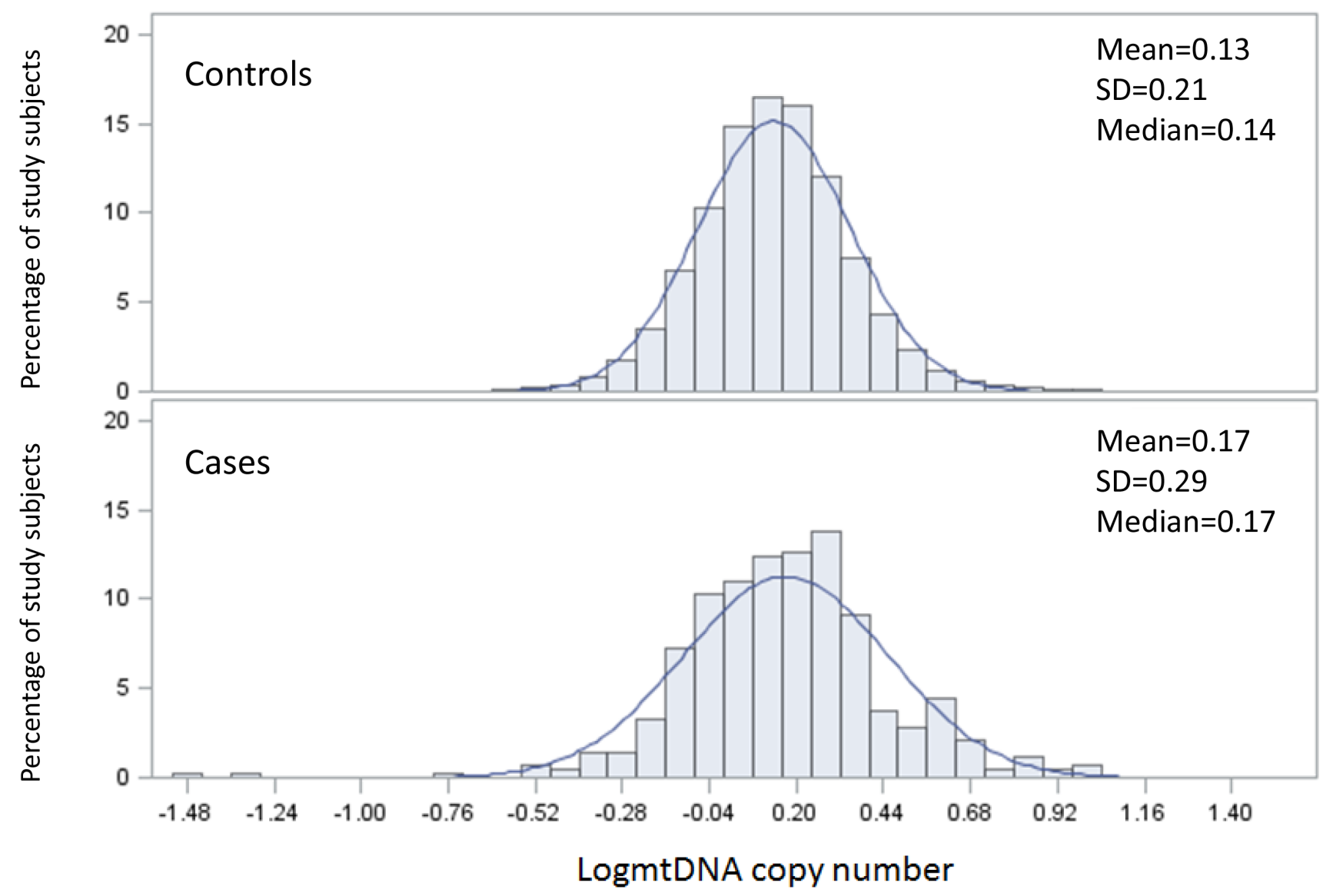

Figure 1: The distribution of mtDNA copy number by case control status. 
Table 1: Log-transformed mitochondrial DNA (mtDNA) copy number by physical and sociodemographic characteristics among 10,373 cancer-free control participants

\begin{tabular}{|c|c|c|c|}
\hline Variable & $N(\%)$ & $\begin{array}{c}\text { Mean mtDNA copy } \\
\text { number (SD) }\end{array}$ & $P$ value \\
\hline Overall & $10,373(100)$ & $0.13(0.21)$ & \\
\hline \multicolumn{4}{|c|}{ Age at enrollment, years $(N=10,373)$} \\
\hline $21-30$ & $2279(21.97)$ & $0.15(0.20)$ & \\
\hline $31-40$ & $3431(33.08)$ & $0.15(0.21)$ & \\
\hline $41-50$ & $2258(21.77)$ & $0.14(0.21)$ & \\
\hline$>50$ & $2405(23.19)$ & $0.11(0.22)$ & $<0.001$ \\
\hline \multicolumn{4}{|l|}{$\operatorname{Sex}(N=10,373)$} \\
\hline Male & $2062(19.88)$ & $0.12(0.21)$ & \\
\hline Female & $8311(80.12)$ & $0.14(0.21)$ & $<0.001$ \\
\hline \multicolumn{4}{|l|}{ Marital status $(N=10,370)$} \\
\hline Married/living together & $8126(78.36)$ & $0.14(0.21)$ & \\
\hline Other & $2234(21.54)$ & $0.13(0.22)$ & 0.024 \\
\hline \multicolumn{4}{|l|}{ Education $(N=10,367)$} \\
\hline Less than high school & $6097(58.81)$ & $0.13(0.22)$ & \\
\hline High school graduate & $2323(22.41)$ & $0.15(0.20)$ & \\
\hline College & $1947(18.78)$ & $0.14(0.21)$ & 0.024 \\
\hline \multicolumn{4}{|l|}{ Place of birth $(N=10,373)$} \\
\hline Mexico & $7813(75.32)$ & $0.14(0.21)$ & \\
\hline US & $2560(24.68)$ & $0.12(0.21)$ & $<0.001$ \\
\hline \multicolumn{4}{|l|}{$\operatorname{BMI}(N=10,349)$} \\
\hline Underweight/normal weight & $1501(14.50)$ & $0.13(0.21)$ & \\
\hline Overweight & $3423(33.08)$ & $0.15(0.22)$ & \\
\hline Obese & $5425(52.42)$ & $0.13(0.21)$ & $<0.001$ \\
\hline \multicolumn{4}{|l|}{ Smoking status $(N=10,371)$} \\
\hline Never & $7571(73.00)$ & $0.14(0.21)$ & \\
\hline Former & $1526(14.71)$ & $0.13(0.21)$ & \\
\hline Current & $1274(12.28)$ & $0.13(0.22)$ & 0.054 \\
\hline \multicolumn{4}{|l|}{ Alcohol drinking $(N=10,351)$} \\
\hline Never & $6993(67.56)$ & $0.14(0.21)$ & \\
\hline Former & $1015(9.81)$ & $0.12(0.22)$ & \\
\hline Current & $2343(22.64)$ & $0.14(0.20)$ & 0.021 \\
\hline \multicolumn{4}{|l|}{ Physical activity $(N=10,283)$} \\
\hline Low & $7471(72.65)$ & $0.13(0.21)$ & \\
\hline Medium + High & $2812(27.35)$ & $0.15(0.20)$ & 0.016 \\
\hline \multicolumn{4}{|l|}{ Sitting, hours per day $(N=10,347)$} \\
\hline$<2$ & $2967(28.67)$ & $0.14(0.21)$ & \\
\hline $2-4$ & $4234(40.92)$ & $0.14(0.21)$ & \\
\hline $4-6$ & 1952 (18.87) & $0.14(0.21)$ & \\
\hline$>6$ hours & $1194(11.54)$ & $0.13(0.21)$ & 0.198 \\
\hline
\end{tabular}

Abbreviations: SD, standard deviation; BMI, body mass index. 
Table 2: Correlations between participant characteristics and log-transformed mitochondrial DNA (mtDNA) copy number by mtDNA copy number quantile rank in cancer-free controls

\begin{tabular}{|c|c|c|c|c|c|}
\hline Variable & Percentile 10 & Percentile 25 & Percentile 50 & Percentile 75 & Percentile 90 \\
\hline Age & $-0.0017^{* *}$ & $-0.0014^{* *}$ & $-0.0013^{* *}$ & $-0.0013^{* *}$ & $-0.0012^{* *}$ \\
\hline \multicolumn{6}{|l|}{ Sex } \\
\hline Female vs. Male & 0.0057 & $0.0149^{*}$ & $0.0228^{* *}$ & $0.0301^{* *}$ & $0.0268^{*}$ \\
\hline \multicolumn{6}{|l|}{ Marital Status } \\
\hline $\begin{array}{l}\text { Other vs. Married/living } \\
\text { together }\end{array}$ & -0.0122 & -0.0113 & -0.0008 & 0.0047 & -0.0006 \\
\hline \multicolumn{6}{|l|}{ Education } \\
\hline College & Reference & & & & \\
\hline Less than high school & -0.0038 & -0.0054 & -0.0008 & -0.0014 & 0.0012 \\
\hline High school graduate & $0.0217^{*}$ & 0.0091 & 0.0049 & 0.002 & 0.0007 \\
\hline \multicolumn{6}{|l|}{ Place of birth } \\
\hline US & Reference & & & & \\
\hline Mexico & 0.0086 & $0.0208^{* *}$ & $0.0172^{* *}$ & $0.0183^{* *}$ & $0.0270^{* *}$ \\
\hline \multicolumn{6}{|l|}{ BMI } \\
\hline Obese & Reference & & & & \\
\hline $\begin{array}{l}\text { Underweight/normal } \\
\text { weight }\end{array}$ & $-0.0194^{*}$ & $-0.0248^{* *}$ & $-0.0146^{*}$ & -0.0023 & 0.0024 \\
\hline Overweight & -0.001 & 0.0066 & $0.0181^{* *}$ & $0.0208^{* *}$ & $0.0233^{* *}$ \\
\hline \multicolumn{6}{|l|}{ Alcohol drinking } \\
\hline Never & Reference & & & & \\
\hline Former & $-0.0333^{* *}$ & -0.0116 & 0.0045 & -0.0007 & 0.0026 \\
\hline Current & -0.0074 & 0.0038 & 0.0049 & 0.0076 & $0.0300^{*}$ \\
\hline \multicolumn{6}{|l|}{ Physical activity } \\
\hline Medium/High vs Low & $-0.0308^{* *}$ & $-0.0148^{* *}$ & -0.0059 & -0.0101 & 0.3373 \\
\hline
\end{tabular}

Abbreviation: BMI, body mass index. ${ }^{*} \%$ significance; ${ }^{* *} 1 \%$ significance.

those in the first quartile (i.e., those with the lowest mtDNA copy number). We also examined the impact of the time between cancer diagnosis and whole blood collection on the relationship between mtDNA copy number and cancer risk, using 5 years as the cutoff point (Table 4). The association between mtDNA copy number and cancer risk was stronger for participants whose cancer was diagnosed within 5 years of blood collection than for those whose cancer was diagnosed later, though it was significant in both groups.

Finally, we conducted an analysis focused on breast cancer, by far the most common cancer in this cohort. Breast cancer risk also increased with mtDNA copy number (as a continuous variable) (HR, 1.23; 95\% CI, 1.14-1.32) but with a slightly higher HR than that estimated for all cancer. With the cohort stratified by the median mtDNA copy number in the control group, the group with high mtDNA copy number had a higher risk of breast cancer than did the group with low mtDNA copy number (HR, 2.63; 95\% CI, 1.74-4.00). Participants in the fourth mtDNA copy number quartile had a higher risk of breast cancer than did those in the first quartile (HR, 3.25; 95\% CI, 1.89-5.60).

\section{DISCUSSION}

To our knowledge, this is the first study to evaluate the relationship between mtDNA copy number and cancer risk among Mexican Americans. Overall, mtDNA copy number was statistically significantly higher among participants with cancer than in the cancer-free cohort group. Among non-cancer participants, mtDNA copy number significantly differed by age, sex, birthplace, BMI, physical activity level, and several variables measuring acculturation, immigration, and socioeconomic status. Risk assessment revealed a statistically significant positive association between high mtDNA copy number and risk of all cancers. These associations were even more pronounced when cases of breast cancer were considered separately and among participants who developed cancer during the first 5 years of follow-up. 
Table 3: Univariate and multivariate analyses of associations between characteristics, log-transformed mtDNA copy number, and cancer risk

\begin{tabular}{|c|c|c|c|c|c|c|}
\hline \multirow[t]{2}{*}{ Variable } & Cases & Controls & HR (95\% CI) & $P$ value & $\begin{array}{c}\text { Adj. HR } \\
(95 \% \text { CI) }\end{array}$ & $P$ value \\
\hline & $N=429(\%)$ & $N=10,373(\%)$ & & & & \\
\hline $\begin{array}{l}\text { Mean age at enrollment, } \\
\text { years (SD) }\end{array}$ & $53.8(14.2)$ & $41.3(13.0)$ & $1.06(1.05-1.06)$ & $<0.001$ & $1.06(1.05-1.06)$ & $<0.001$ \\
\hline \multicolumn{7}{|l|}{ Sex } \\
\hline Female & $326(75.99)$ & $8311(80.12)$ & Reference & & & \\
\hline Male & $103(24.01)$ & $2062(19.88)$ & $1.25(1.00-1.56)$ & 0.048 & & \\
\hline \multicolumn{7}{|l|}{ Marital status } \\
\hline $\begin{array}{l}\text { Married/living as } \\
\text { married }\end{array}$ & $311(72.49)$ & $8126(78.44)$ & Reference & & & \\
\hline Other & $118(27.51)$ & $2234(21.56)$ & $1.41(1.14-1.74)$ & 0.004 & & \\
\hline \multicolumn{7}{|l|}{ Education } \\
\hline College & $74(17.25)$ & 1947 (18.78) & Reference & & & \\
\hline Less than high school & $272(63.40)$ & $6097(58.81)$ & $1.11(0.87-1.42)$ & 0.397 & & \\
\hline High school graduate & $83(19.35)$ & $2323(22.41)$ & $1.22(0.94-1.58)$ & 0.132 & & \\
\hline \multicolumn{7}{|l|}{ Place of birth } \\
\hline US & $173(40.33)$ & $2560(24.68)$ & Reference & & Reference & \\
\hline Mexico & $256(59.67)$ & $7813(75.32)$ & $0.52(0.43-0.63)$ & $<0.001$ & $0.74(0.60-0.90)$ & 0.003 \\
\hline \multicolumn{7}{|l|}{ BMI } \\
\hline $\begin{array}{l}\text { Underweight/Normal } \\
\text { weight }\end{array}$ & $50(11.66)$ & $1501(14.50)$ & Reference & & Reference & \\
\hline Overweight & $146(34.03)$ & $3423(33.08)$ & $1.37(0.99-1.90)$ & 0.055 & $1.25(0.90-1.72)$ & 0.184 \\
\hline Obese & $233(54.31)$ & $5425(52.42)$ & $1.49(1.09-2.03)$ & 0.012 & $1.40(1.03-1.91)$ & 0.033 \\
\hline \multicolumn{7}{|l|}{ Smoking status } \\
\hline Never & $255(59.44)$ & $7571(73.00)$ & Reference & & Reference & \\
\hline Former & $94(21.91)$ & $1526(14.71)$ & $1.84(1.43-2.37)$ & $<0.001$ & $1.23(0.96-1.56)$ & 0.096 \\
\hline Current & $80(18.65)$ & $1274(12.28)$ & $1.87(1.47-2.36)$ & $<0.001$ & $1.86(1.44-2.40)$ & $<0.001$ \\
\hline \multicolumn{7}{|l|}{ Alcohol drinking } \\
\hline Never & $270(62.94)$ & $6993(67.56)$ & Reference & & & \\
\hline Former & $71(16.55)$ & $1015(9.81)$ & $0.96(0.76-1.22)$ & 0.753 & & \\
\hline Current & $88(20.51)$ & $2343(22.64)$ & $1.75(1.35-2.28)$ & $<0.001$ & & \\
\hline \multicolumn{7}{|l|}{ Physical activity } \\
\hline Low & $296(77.28)$ & $7763(73.13)$ & Reference & & & \\
\hline Medium/High & $87(22.72)$ & $2852(26.87)$ & $0.83(0.66-1.04)$ & 0.096 & & \\
\hline \multicolumn{7}{|l|}{ Sitting time per day, $\mathrm{h}$} \\
\hline$<2$ & $115(26.81)$ & $2967(28.67)$ & reference & & & \\
\hline $2-4$ & $175(40.79)$ & $4234(40.92)$ & $1.04(0.82-1.31)$ & 0.763 & & \\
\hline $4-6$ & $76(17.72)$ & $1952(18.87)$ & $1.01(0.76-1.35)$ & 0.945 & & \\
\hline $6+$ hours & $63(14.69)$ & $1194(11.54)$ & $1.29(0.95-1.76)$ & 0.105 & & \\
\hline \multicolumn{7}{|l|}{ mtDNA copy number } \\
\hline Continuous (unit $=0.1$ ) & $427(100)$ & $10,373(100)$ & $1.10(1.05-1.14)$ & $<0.001$ & $1.13(1.09-1.17)$ & $<0.001$ \\
\hline
\end{tabular}


Table 4: Multivariate analysis of association between log-transformed mtDNA copy number and cancer risk

\begin{tabular}{|c|c|c|c|c|}
\hline \multicolumn{5}{|c|}{ All cancers } \\
\hline $\operatorname{logmtDNA}$ & Cases, $N(\%)$ & Controls, $N(\%)$ & Adj, HR (95\% CI) $)^{*}$ & $P$ value \\
\hline Continuous (unit $=0.1$ ) & $427(100)$ & $10,373(100)$ & $1.13(1.09-1.17)$ & $<0.001$ \\
\hline \multicolumn{5}{|l|}{ By median } \\
\hline$<0.13$ & $188(44.03)$ & $5081(48.98)$ & Reference & \\
\hline$\geq 0.13$ & $239(55.97)$ & $5292(51.02)$ & $1.71(1.41-2.07)$ & $<0.001$ \\
\hline \multicolumn{5}{|l|}{ By quartile } \\
\hline $1 \mathrm{st}$ & $107(25.06)$ & $2468(23.79)$ & Reference & \\
\hline $2 \mathrm{nd}$ & $81(18.97)$ & $2613(25.19)$ & $1.02(0.76-1.36)$ & 0.906 \\
\hline $3 \mathrm{rd}$ & $90(21.08)$ & $2643(25.48)$ & $1.32(0.99-1.75)$ & 0.055 \\
\hline 4 th & $149(34.89)$ & $2649(25.54)$ & $2.12(1.65-2.73)$ & $<0.001$ \\
\hline$P$ for trend & & & & $<0.001$ \\
\hline \multicolumn{5}{|c|}{ All cancers: cancer diagnosed $\leq \mathbf{5}$ years after whole blood collection } \\
\hline logmtDNA & Cases, $N(\%)$ & Controls, $N(\%)$ & $\begin{array}{c}\text { Adj. HR } \\
(95 \% \text { CI })^{*}\end{array}$ & $P$ value \\
\hline Continuous (unit $=0.1$ ) & $188(100)$ & $3420(100)$ & $1.21(1.13-1.29)$ & $<0.001$ \\
\hline \multicolumn{5}{|l|}{ By median } \\
\hline$<0.13$ & $67(35.64)$ & $1635(47.81)$ & Reference & \\
\hline$\geq 0.13$ & $121(64.36)$ & $1785(52.19)$ & $2.18(1.61-2.96)$ & $<0.001$ \\
\hline \multicolumn{5}{|l|}{ By quartile } \\
\hline $1 \mathrm{st}$ & $34(18.09)$ & 707 (20.67) & Reference & \\
\hline 2 nd & $33(17.55)$ & $928(27.13)$ & $0.96(0.60-1.55)$ & 0.873 \\
\hline $3 \mathrm{rd}$ & $53(28.19)$ & $980(28.65)$ & $1.64(1.06-2.54)$ & 0.026 \\
\hline 4 th & $68(36.17)$ & $805(23.54)$ & $2.83(1.86-4.32)$ & $<0.001$ \\
\hline$P$ for trend & & & & $<0.001$ \\
\hline \multicolumn{5}{|c|}{ All cancers: cancer diagnosed $>5$ years after whole blood collection } \\
\hline Continuous (unit $=0.1$ ) & $205(100)$ & $6572(100)$ & $1.09(1.03-1.15)$ & 0.002 \\
\hline \multicolumn{5}{|l|}{ By median } \\
\hline$<0.13$ & $105(51.22)$ & $3299(50.20)$ & Reference & \\
\hline$\geq 0.13$ & $100(48.78)$ & $3273(49.80)$ & $1.44(1.09-1.90)$ & 0.010 \\
\hline $1 \mathrm{st}$ & $68(33.17)$ & $1707(25.97)$ & Reference & \\
\hline 2 nd & $37(18.05)$ & $1592(24.22)$ & $0.80(0.53-1.19)$ & 0.263 \\
\hline $3 \mathrm{rd}$ & $32(15.61)$ & $1544(23.49)$ & $0.99(0.58-1.34)$ & 0.549 \\
\hline 4 th & $68(33.17)$ & $1729(26.31)$ & $1.74(1.23-2.44)$ & 0.002 \\
\hline$P$ for trend & & & & 0.003 \\
\hline \multicolumn{5}{|c|}{ Breast cancer only } \\
\hline Continuous (unit $=0.1$ ) & $102(100)$ & $8311(100)$ & $1.23(1.14-1.32)$ & $<0.001$ \\
\hline \multicolumn{5}{|l|}{ By median } \\
\hline$<0.13$ & $33(32.04)$ & $3988(47.98)$ & Reference & \\
\hline$\geq 0.13$ & $69(67.96)$ & $4323(52.02)$ & $2.63(1.73-4.00)$ & $<0.001$ \\
\hline $1 \mathrm{st}$ & $19(18.63)$ & $1939(23.33)$ & Reference & \\
\hline $2 \mathrm{nd}$ & $14(13.73)$ & $2049(24.65)$ & $0.92(0.46-1.83)$ & 0.808 \\
\hline $3 \mathrm{rd}$ & $24(23.53)$ & $2131(25.64)$ & $1.80(0.98-3.30)$ & 0.058 \\
\hline 4 th & $45(44.12)$ & $2192(26.37)$ & $3.25(1.89-5.60)$ & $<0.001$ \\
\hline$P$ for trend & & & & $<0.001$ \\
\hline
\end{tabular}

*Adjusted by age, birth place, BMI category, and smoking status. 
Although all our study participants are Mexican Americans, given the critical role of mitochondria in the biological system, we don't expect to see large racial or ethnic differences in comparison of the results from this study to those conducted in other race or ethnic groups. In fact, the observed relationship between mtDNA copy number and breast cancer risk is similar with other studies conducted in other race and ethnic groups, including Caucasian, Chinese, etc $[5,6,29,30]$. In addition, the impact of blood drawn on the association observed in this study is also reported in previous studies $[5,11]$.

However, two recent meta-analyses found no significant association between mtDNA copy number and all-cancer risk [31, 32]. The discrepancy between the results of those studies and ours may be attributable to the heterogeneity of the cancer sites in the study samples. Those meta-analyses demonstrated that the relationship between mtDNA copy number and cancer risk markedly varied by cancer site, with the most consistent relationships observed in lymphoma and breast cancer. In our study, nearly a quarter of the cancer cases were breast cancer, substantially higher than in the 2 metaanalyses. We observed a significant positive association between mtDNA copy number and breast cancer risk. This observation is consistent with other reports from the literature $[5,6,29,30]$. The discrepancy may also come from the difference in study design. The meta-analyses include both case-control and nested case-control studies, and our study is a prospective cohort study, which provide us the ability to determine temporal exposure in relation to disease and evaluate the possibility of reverse causation. Interestingly, studies have shown that changes in mtDNA content might be a genetic event in the progression of carcinogenesis. For example, mtDNA copy number was higher in early-stage ovarian tumors, where latestage tumors had lower mtDNA copy number [33]. And in gastric cancer, mtDNA instability may play a role in early events leading to cancer progression [34]. As the associations we observe are more pronounced among cases occurring earlier during follow-up, our results suggest increased levels of mtDNA copy number may be an early biomarker of subclinical cancer in Mexican Americans. Our observations are consistent with those of 3 previous reports $[5,11]$. Clearly, more studies are needed to further assess the biological significance of mtDNA copy number difference between the cases and controls. Additionally, our study showed that differences in the social-demographic characteristics, acculturation and immigration experiences, and health behaviors of the study populations may also contribute to the discrepancy.

We observed blood mtDNA copy number was inversed associated with age among the non-cancer participants. This finding is consistent with the results of several previous studies of various organ tissues [29, 30, 35-39]. We also observed a sex difference in mtDNA copy number in the control group. Similar sex differences were reported in previous studies [12, 16, 40]. Our study is the first to report differences in mtDNA copy number by birthplace, with Mexico-born participants having higher mtDNA copy numbers than US-born participants. We also found that mtDNA copy number was positively correlated with the duration of residence in the United States among Mexico-born participants. Even among US-born participants, mtDNA copy number was positively correlated with language acculturation. Although the underlying link between mtDNA copy number and acculturation is unknown, we speculate that the difference may be partially a result of the stresses of immigration and acculturation on the Mexico-born participants. Moreover, immigrants tend to have low socioeconomic status and to live in poor and enclosed neighborhoods. Those factors may translate into financial stress and stress from discrimination. In fact, researchers are increasingly interested in understanding how mitochondrial dysfunction is involved in stress and its related disorders. For example, in a recent study, early-life experiences of adversity and lifetime psychopathology were found to be associated with higher mtDNA copy number $(P<0.001)$ [41]. Similarly, Otsuka et al. [42] reported that mtDNA copy number was significantly higher among individuals who committed suicide than in controls.

In the current study, we found that control participants who were overweight had higher mtDNA copy numbers than did those who were obese or who were underweight or normal weight. Similar trend was also reported in prostate cancer patients [43]. Due to the limitation in DNA repair capacity, mitochondria cannot remove or repair DNA damage caused by ROS. To compensate for the damage, healthy mitochondria increase their copy number to counterbalance the metabolic defects in mitochondria carrying mutated mtDNA and the resulting impaired respiratory system [44, 45]. However, mitochondria are the main sites for fatty acid $\beta$-oxidation. Loss of mitochondrial enzymes can cause obesity in mice [46]. Thus, our finding might indicate a defect in mitochondrial function due to increased BMI, by which mtDNA copy numbers have to be increased to compensate the loss of healthy mitochondria. However, once BMI reaches above the threshold, mtDNA copy numbers can no longer be increased to cope with the stress caused by fatty acid metabolism. Evidently, more study is wanted to further understand how these factors may influence mtDNA copy number levels.

Additionally, we observed that participants with medium or high levels of physical activity had higher mtDNA copy numbers than did those with low levels of physical activity. Our observation is generally consistent with literature reports. For example, being physically active was found to be associated with higher blood mtDNA copy number in postmenopausal women [47]. Being physical active can increase mitochondrial function in skeletal muscle $[48,49]$. Additionally, regular exercise can prevent the ageing process as well as the progression 
of age-related chronic diseases. While the biological relationships are not fully revealed, anti-oxidative and antiinflammatory effects are recognized to be major players $[48,50]$. In bloods, the mitochondrial transmembrane potential, not only a critical immune system element but also a functional marker of energy status and viability, is affected by exercise $[51,52]$. Thus, regular exercise boosts the immune system and reduces inflammatory responses by augmenting blood mitochondrial functions [53].

The major strengths of this study include its large sample size, detailed epidemiologic questionnaire data, and unique Mexican American study population. One weakness of our study is that we were unable to obtain repeated measures of mtDNA copy number because one time quantification may not echo mtDNA copy number over a long period. Lemnrau et al. [29] compared mtDNA copy number from blood samples collected approximately 6 years apart and found wide temporal variation. No matched tumor and normal tissues, which would have enabled us to compare mtDNA copy number in target and proxy tissues, were available. While the amount of mtDNA in various cell types is generally consistent, mtDNA copy number shows significant variation by cell type. In addition, there is a possibility that the results from this study may be biased by multiple sources of non-lineage DNA in peripheral blood, such as platelets and cell-free DNAs. Unfortunately, in our study, we don't have the data on platelet and white blood cell count when the blood was drawn. Finally, we have to be very cautious to generalize the findings from this study to other population. Other cohorts of Mexican Americans are needed to validate our findings. Nevertheless, our study is the first prospectively designed study to show a positive association between blood mtDNA copy number and allcancer risk. Although blood mtDNA copy number can be affected by various factors, it still have clinical relevance including risk prediction and stratification. Further research is needed to evaluate factors associated with stress, aging, and oxidative damage that influence mtDNA copy number and to define the underlying molecular mechanisms linking blood mtDNA copy number and cancer risk.

\section{MATERIALS AND METHODS}

\section{Study population}

The samples used in this study were obtained from individuals in a large population-based cohort of Mexicanorigin households recruited in the Houston, Texas area. Detailed description of the cohort has been illustrated previously [54]. The informed consent was obtained before the interview from each study participant. The incidence of cancer was confirmed with the Texas Cancer Registry. The study was approved by the Institutional Review Board of MD Anderson Cancer Center. All methods were performed in accordance with the relevant guidelines and regulations.

\section{Determination of mtDNA copy number}

Genomic DNA was extracted from whole blood for all the samples by use of QIAamp DNA Mini kits (Qiagen, Valencia, CA). We used a real-time quantitative polymerase chain reaction (PCR) to determine mtDNA copy number. This method, which has high interassay reliability, is detailed in our previous publications $[16,40]$. Two pairs of primers were used in 2 steps for relative quantification of mtDNA. One primer pair was used to amplify the mitochondrially encoded NADH:ubiquinone oxidoreductase core subunit 1 (MTND1) gene. The other primer pair was used to amplify the single-copy nuclear human globulin $(H G B)$ gene. SYBR-green was used in the analysis. The PCRs for two genes were executed on separate 96-well plates with the same samples in the same well positions to avoid possible position effects. A diluted reference DNA, a negative control DNA, and a calibrator DNA were included in each run to generate the standard curves. For each standard curve, the DNA sample was consecutively diluted 1:2 to yield a 7-point standard curve between 0.3125 and $20 \mathrm{ng}$ of DNA. The $\mathrm{R}^{2}$ value for each standard curve was 0.99 or higher and the average slope of each standard curve was 3.45. Standard deviations for the threshold cycle $(\mathrm{Ct})$ value were set at 0.25 . If the $\mathrm{Ct}$ value was higher than this cutoff, the test was repeated.

\section{Statistical analysis}

We used the statistical software package SAS version 9.4 (SAS, Cary, NC) for analysis. Because the mtDNA copy number data were not normally distributed in the control group, we performed the analysis using logtransformed data. First, we evaluated whether mtDNA copy number differed according to selected characteristics in a cancer-free control group. The Student $t$ test was used for 2-level dichotomous variables, and analysis of variance was used for variables with more than 2 levels. Next, to further assess the relationships between selected demographic variables and mtDNA copy number in the control group, we performed multivariate unconditional quantile regression analysis. Unconditional quantile regression estimates the effects at different points of the distribution of the endogenous variable, for example at the 10th, 25th, 50th, 75th, and 90th percentiles. This test tells us how the independent variable affects the entire distribution of the dependent variable, not only its mean. Age, sex, marital status, education level, place of birth, body mass index (BMI), alcohol use, and physical activity were included in the unconditional quantile regression model.

To assess relationships between mtDNA copy number and variables measuring acculturation and socioeconomic status in the control group, we performed multivariate linear regression analysis. The model included a language acculturation score; preference for 
Mexican or US food, friends, social activity, heritage, and holidays; income; home ownership; car ownership; health insurance status; age; sex; and birthplace. For participants born in Mexico, the number of years living in the United States and age of immigration were also included.

Finally, associations among cancer incidence, selected demographic characteristics, and mtDNA copy number were assessed using univariate and multivariableadjusted Cox proportional hazards regression models. Mitochondrial DNA copy number was analyzed as both a continuous and a categorical variable. For categorical variables, cutoff points were set at the quartile values in the cancer-free control group. Adjusted hazard ratios (HRs) and 95\% confidence intervals (CIs) were estimated, and potential confounding factors were adjusted for as appropriate. All statistical tests were 2 -sided, and $P$ values of less than 0.05 were considered statistically significant.

\section{Author contributions}

Author contributions were as follows: H.Z, C.W.H, and X.W designed the research. D.C performed the experiments. Y.Y and H.Z analyzed the data. H.Z, C.W.H, and X.W provided materials and resources. H.Z and J.S wrote the paper, with input from the other co-authors.

\section{ACKNOWLEDGMENTS}

None declared.

\section{CONFLICTS OF INTEREST}

None declared.

\section{FUNDING}

The Cohort receives funds collected pursuant to the Comprehensive Tobacco Settlement of 1998 and appropriated by the 76th legislature to The University of Texas MD Anderson Cancer Center. This work was supported in part by Center for Translational and Public Health Genomics, the Dan Duncan Family Institute for Risk Assessment and Cancer Prevention. The funders did not contribute to the design and conduct of the study; the collection, analysis, or interpretation of the data; or the preparation, review, or approval of the manuscript.

\section{REFERENCES}

1. Larsson NG, Clayton DA. Molecular genetic aspects of human mitochondrial disorders. Annu Rev Genet. 1995; 29:151-78. https://doi.org/10.1146/annurev.ge.29.120195.001055.

2. Liu CS, Tsai CS, Kuo CL, Chen HW, Lii CK, Ma YS, Wei YH. Oxidative stress-related alteration of the copy number of mitochondrial DNA in human leukocytes. Free Radic Res. 2003; 37:1307-17. https://doi.org/10.1080/107157603100016 21342.

3. Wallace DC. Mitochondrial diseases in man and mouse. Science. 1999; 283:1482-88. https://doi.org/10.1126/ science.283.5407.1482.

4. Carew JS, Huang P. Mitochondrial defects in cancer. Mol Cancer. 2002; 1:9. https://doi.org/10.1186/1476-4598-1-9.

5. Thyagarajan B, Wang R, Nelson H, Barcelo H, Koh WP, Yuan JM. Mitochondrial DNA copy number is associated with breast cancer risk. PLoS One. 2013; 8:e65968. https://doi. org/10.1371/journal.pone.0065968.

6. Shen J, Platek M, Mahasneh A, Ambrosone CB, Zhao H. Mitochondrial copy number and risk of breast cancer: a pilot study. Mitochondrion. 2010; 10:62-68. https://doi. org/10.1016/j.mito.2009.09.004.

7. Lan Q, Lim U, Liu CS, Weinstein SJ, Chanock S, Bonner MR, Virtamo J, Albanes D, Rothman N. A prospective study of mitochondrial DNA copy number and risk of nonHodgkin lymphoma. Blood. 2008; 112:4247-49. https://doi. org/10.1182/blood-2008-05-157974.

8. Hosnijeh FS, Lan Q, Rothman N, San Liu C, Cheng WL, Nieters A, Guldberg P, Tjonneland A, Campa D, Martino A, Boeing H, Trichopoulou A, Lagiou P, et al. Mitochondrial DNA copy number and future risk of B-cell lymphoma in a nested case-control study in the prospective EPIC cohort. Blood. 2014; 124:530-35. https://doi.org/10.1182/ blood-2013-10-532085.

9. Hosgood HD 3rd, Liu CS, Rothman N, Weinstein SJ, Bonner MR, Shen M, Lim U, Virtamo J, Cheng WL, Albanes D, Lan Q. Mitochondrial DNA copy number and lung cancer risk in a prospective cohort study. Carcinogenesis. 2010; 31:847-49. https://doi.org/10.1093/carcin/bgq045.

10. Hofmann JN, Hosgood HD 3rd, Liu CS, Chow WH, Shuch B, Cheng WL, Lin TT, Moore LE, Lan Q, Rothman N, Purdue MP. A nested case-control study of leukocyte mitochondrial DNA copy number and renal cell carcinoma in the Prostate, Lung, Colorectal and Ovarian Cancer Screening Trial. Carcinogenesis. 2014; 35:1028-31. https://doi.org/10.1093/ carcin/bgt495.

11. Lynch SM, Weinstein SJ, Virtamo J, Lan Q, Liu CS, Cheng WL, Rothman N, Albanes D, Stolzenberg-Solomon RZ. Mitochondrial DNA copy number and pancreatic cancer in the alpha-tocopherol beta-carotene cancer prevention study. Cancer Prev Res (Phila). 2011; 4:1912-19. https://doi. org/10.1158/1940-6207.CAPR-11-0002.

12. Thyagarajan B, Wang R, Barcelo H, Koh WP, Yuan JM. Mitochondrial copy number is associated with colorectal cancer risk. Cancer Epidemiol Biomarkers Prev. 2012; 21:1574-81. https://doi.org/10.1158/1055-9965. EPI-12-0138-T.

13. Zhang J, Li D, Qu F, Chen Y, Li G, Jiang H, Huang X, Yang H, Xing J. Association of leukocyte mitochondrial 
DNA content with glioma risk: evidence from a Chinese case-control study. BMC Cancer. 2014; 14:680. https://doi. org/10.1186/1471-2407-14-680.

14. Shen J, Song R, Lu Z, Zhao H. Mitochondrial DNA copy number in whole blood and glioma risk: A case control study. Mol Carcinog. 2016; 55:2089-94. https://doi.org/10.1002/ mc.22453.

15. Huang B, Gao YT, Shu XO, Wen W, Yang G, Li G, Courtney R, Ji BT, Li HL, Purdue MP, Zheng W, Cai Q. Association of leukocyte mitochondrial DNA copy number with colorectal cancer risk: Results from the Shanghai Women's Health Study. Cancer Epidemiol Biomarkers Prev. 2014; 23:2357-65. https:// doi.org/10.1158/1055-9965.EPI-14-0297.

16. Xing J, Chen M, Wood CG, Lin J, Spitz MR, Ma J, Amos CI, Shields PG, Benowitz NL, Gu J, de Andrade M, Swan GE, Wu X. Mitochondrial DNA content: its genetic heritability and association with renal cell carcinoma. J Natl Cancer Inst. 2008; 100:1104-12. https://doi.org/10.1093/jnci/djn213.

17. Koebnick C, Langer-Gould AM, Gould MK, Chao CR, Iyer RL, Smith N, Chen W, Jacobsen SJ. Sociodemographic characteristics of members of a large, integrated health care system: comparison with US Census Bureau data. Perm J. 2012; 16:37-41. https://doi.org/10.7812/TPP/12-031.

18. Rossen LM. Neighbourhood economic deprivation explains racial/ethnic disparities in overweight and obesity among children and adolescents in the U.S.A. J Epidemiol Community Health. 2014; 68:123-29. https://doi.org/10.1136/ jech-2012-202245.

19. Gallo LC, Fortmann AL, de Los Monteros KE, Mills PJ, Barrett-Connor E, Roesch SC, Matthews KA. Individual and neighborhood socioeconomic status and inflammation in Mexican American women: what is the role of obesity? Psychosom Med. 2012; 74:535-42. https://doi.org/10.1097/ PSY.0b013e31824f5f6d.

20. Lee JY, Lee DC, Im JA, Lee JW. Mitochondrial DNA copy number in peripheral blood is independently associated with visceral fat accumulation in healthy young adults. Int J Endocrinol. 2014; 2014:586017. https://doi. org/10.1155/2014/586017.

21. Caballero AE. Understanding the Hispanic/Latino patient. Am J Med. 2011; 124:S10-15. https://doi.org/10.1016/j. amjmed.2011.07.018.

22. Al Snih S, Fisher MN, Raji MA, Markides KS, Ostir GV, Goodwin JS. Diabetes mellitus and incidence of lower body disability among older Mexican Americans. J Gerontol A Biol Sci Med Sci. 2005; 60:1152-56. https://doi.org/10.1093/ gerona/60.9.1152.

23. Ventura H, Pina IL, Lavie CJ. Hypertension and antihypertensive therapy in Hispanics and Mexican Americans living in the United States. Postgrad Med. 2011; 123:46-57. https://doi.org/10.3810/pgm.2011.11.2494.

24. Centers for Disease Control and Prevention (CDC). Hypertension-related mortality among Hispanic subpopulations - United States, 1995-2002. MMWR Morb Mortal Wkly Rep. 2006; 55:177-80.

25. Schneider MG, Chiriboga DA. Associations of stress and depressive symptoms with cancer in older Mexican Americans. Ethn Dis. 2005; 15:698-704.

26. Sullivan MM, Rehm R. Mental health of undocumented Mexican immigrants: a review of the literature. ANS Adv Nurs Sci. 2005; 28:240-51. https://doi. org/10.1097/00012272-200507000-00006.

27. Picard M, Juster RP, McEwen BS. Mitochondrial allostatic load puts the 'gluc' back in glucocorticoids. Nat Rev Endocrinol. 2014; 10:303-10. https://doi.org/10.1038/nrendo.2014.22.

28. Takabayashi A, Kanai M, Kawai Y, Iwata S, Sasada T, Obama $\mathrm{K}$, Taki Y. Change in mitochondrial membrane potential in peripheral blood lymphocytes, especially in natural killer cells, is a possible marker for surgical stress on the immune system. World J Surg. 2003; 27:659-65. https://doi.org/10.1007/ s00268-003-6926-7.

29. Lemnrau A, Brook MN, Fletcher O, Coulson P, Tomczyk K, Jones M, Ashworth A, Swerdlow A, Orr N, Garcia-Closas M. Mitochondrial dna copy number in peripheral blood cells and risk of developing breast cancer. Cancer Res. 2015; 75:2844 50. https://doi.org/10.1158/0008-5472.CAN-14-1692.

30. Shen J, Wan J, Song R, Zhao H. Peripheral blood mitochondrial DNA copy number, length heteroplasmy and breast cancer risk: a replication study. Carcinogenesis. 2015; 36:1307-13. https://doi.org/10.1093/carcin/bgv130.

31. Hu L, Yao X, Shen Y. Altered mitochondrial DNA copy number contributes to human cancer risk: evidence from an updated meta-analysis. Sci Rep. 2016; 6:35859. https://doi. org/10.1038/srep35859.

32. Mi J, Tian G, Liu S, Li X, Ni T, Zhang L, Wang B. The relationship between altered mitochondrial DNA copy number and cancer risk: a meta-analysis. Sci Rep. 2015; 5:10039. https://doi.org/10.1038/srep10039.

33. Wang Y, Liu VW, Xue WC, Cheung AN, Ngan HY. Association of decreased mitochondrial DNA content with ovarian cancer progression. Br J Cancer. 2006; 95:1087-91. https://doi.org/10.1038/sj.bjc.6603377.

34. Jeong CW, Lee JH, Sohn SS, Ryu SW, Kim DK. Mitochondrial microsatellite instability in gastric cancer and gastric epithelial dysplasia as a precancerous lesion. Cancer Epidemiol. 2010; 34:323-27. https://doi.org/10.1016/j.canep.2010.03.015.

35. Chen XP, Mata M, Kelley M, Glorioso JC, Fink DJ. The relationship of herpes simplex virus latency associated transcript expression to genome copy number: a quantitative study using laser capture microdissection. J Neurovirol. 2002; 8:204-10. https://doi.org/10.1080/13550280290049642.

36. Hayakawa M, Torii K, Sugiyama S, Tanaka M, Ozawa T. Age-associated accumulation of 8-hydroxydeoxyguanosine in mitochondrial DNA of human diaphragm. Biochem Biophys Res Commun. 1991; 179:1023-29. https://doi. org/10.1016/0006-291X(91)91921-X. 
37. Welle S, Bhatt K, Shah B, Needler N, Delehanty JM, Thornton CA. Reduced amount of mitochondrial DNA in aged human muscle. J Appl Physiol (1985). 2003; 94:1479-84. https://doi. org/10.1152/japplphysiol.01061.2002.

38. Pollack M, Leeuwenburgh C. Apoptosis and aging: role of the mitochondria. J Gerontol A Biol Sci Med Sci. 2001; 56:B47582. https://doi.org/10.1093/gerona/56.11.B475.

39. Drouet M, Lauthier F, Charmes JP, Sauvage P, Ratinaud MH. Age-associated changes in mitochondrial parameters on peripheral human lymphocytes. Exp Gerontol. 1999; 34:84352. https://doi.org/10.1016/S0531-5565(99)00058-3.

40. Melkonian SC, Wang X, Gu J, Matin SF, Tannir NM, Wood $\mathrm{CG}, \mathrm{Wu} \mathrm{X}$. Mitochondrial DNA copy number in peripheral blood leukocytes and the risk of clear cell renal cell carcinoma. Carcinogenesis. 2015; 36:249-55. https://doi.org/10.1093/ carcin/bgu248.

41. Tyrka AR, Parade SH, Price LH, Kao HT, Porton B, Philip NS, Welch ES, Carpenter LL. Alterations of mitochondrial DNA copy number and telomere length with early adversity and psychopathology. Biol Psychiatry. 2016; 79:78-86. https:// doi.org/10.1016/j.biopsych.2014.12.025.

42. Otsuka I, Izumi T, Boku S, Kimura A, Zhang Y, Mouri K, Okazaki S, Shiroiwa K, Takahashi M, Ueno Y, Shirakawa O, Sora I, Hishimoto A. Aberrant telomere length and mitochondrial DNA copy number in suicide completers. Sci Rep. 2017; 7:3176. https://doi.org/10.1038/ s41598-017-03599-8.

43. Tu H, Gu J, Meng QH, Kim J, Davis JW, He Y, Wagar EA, Thompson TC, Logothetis CJ, Wu X. Mitochondrial DNA copy number in peripheral blood leukocytes and the aggressiveness of localized prostate cancer. Oncotarget. 2015; 6:41988-96. https://doi.org/10.18632/oncotarget.5889.

44. Yu M. Generation, function and diagnostic value of mitochondrial DNA copy number alterations in human cancers. Life Sci. 2011; 89:65-71. https://doi.org/10.1016/j. 1fs.2011.05.010.

45. Lee HC, Wei YH. Mitochondrial biogenesis and mitochondrial DNA maintenance of mammalian cells under oxidative stress. Int J Biochem Cell Biol. 2005; 37:822-34. https://doi. org/10.1016/j.biocel.2004.09.010.
46. Quirós PM, Ramsay AJ, Sala D, Fernandez-Vizarra E, Rodriguez F, Peinado JR, Fernandez-Garcia MS, Vega JA, Enriquez JA, Zorzano A, Lopez-Otin C. Loss of mitochondrial protease OMA1 alters processing of the GTPase OPA1 and causes obesity and defective thermogenesis in mice. EMBO J. 2012; 31:2117-33. https://doi.org/10.1038/emboj.2012.70.

47. Chang YK, Kim DE, Cho SH, Kim JH. Association between leukocyte mitochondrial DNA copy number and regular exercise in postmenopausal women. Korean J Fam Med. 2016; 37:334-39. https://doi.org/10.4082/kjfm.2016.37.6.334.

48. Carter HN, Chen CC, Hood DA. Mitochondria, muscle health, and exercise with advancing age. Physiology (Bethesda). 2015; 30:208-23. https://doi.org/10.1152/physiol.00039.2014.

49. Cobley JN, Moult PR, Burniston JG, Morton JP, Close GL. Exercise improves mitochondrial and redox-regulated stress responses in the elderly: better late than never! Biogerontology. 2015; 16:249-64. https://doi.org/10.1007/s10522-014-9546-8.

50. Sallam N, Laher I. Exercise modulates oxidative stress and inflammation in aging and cardiovascular diseases. Oxid Med Cell Longev. 2016; 2016:7239639. https://doi. org/10.1155/2016/7239639.

51. Hsu TG, Hsu KM, Kong CW, Lu FJ, Cheng H, Tsai K. Leukocyte mitochondria alterations after aerobic exercise in trained human subjects. Med Sci Sports Exerc. 2002; 34:43842. https://doi.org/10.1097/00005768-200203000-00009.

52. Kulkarni OP, Lichtnekert J, Anders HJ, Mulay SR. The immune system in tissue environments regaining homeostasis after injury: is "inflammation" always inflammation? Mediators Inflamm. 2016; 2016:2856213. https://doi. org/10.1155/2016/2856213.

53. Kruger K, Mooren FC. Exercise-induced leukocyte apoptosis. Exerc Immunol Rev. 2014; 20:117-34.

54. Chow WH, Chrisman M. C RD, Ye Y, Gomez H, Dong Q, Anderson CE, Chang S, Strom S, Zhao H, Wu X. Cohort Profile: The Mexican American Mano a Mano Cohort. Int J Epidemiol. 2017; 46:e3. https://doi.org/10.1093/ije/dyv016. 